\title{
High Pressure Measurements of Density, Velocity of Sound, and Bulk Moduli of Pentane and 2-Methylbutane and Their Mixtures
}

\author{
James C. Houck \\ Institute for Basic Standards, National Bureau of Standards, Washington, D.C. 20234
}

(May 23, 1974)

\begin{abstract}
Dilatometric and ultrasonic measurements were made on mixtures of pentane and 2-methylbutane to give density, relative volume, isothermal bulk modulus, velocity of sound, and adiabatic bulk modulus to pressure of 24 kilobars $\left(2.4 \times 10^{9} \mathrm{~N} / \mathrm{m}^{2}\right)$.
\end{abstract}

Key words: Bulk modulus; compressibility; density; dilatometric measurements; high pressure; liquids; 2-methylbutane; pentane; ultrasonics.

\section{Introduction}

This report supplements a previous report $[1]^{1}$ which gave the results of measurements of mixtures of 2-methylbutane and aviation instrument oil to 20 kilobars. ${ }^{2}$ Mixtures of pentane and 2-methylbutane are used as hydrostatic pressure fluids to 50 kilobars [2]. These pressures are well above the freezing pressures of the individual fluids. A study was undertaken to determine the properties of the mixtures as a function of pressure at room temperature. The freezing pressure at room temperature, given by Reeves et al [4], is $15 \mathrm{kbar}$ for pentane and is $21 \mathrm{kbar}$ for 2-methylbutane. The freezing pressure of pentane was measured to be $17.55 \pm 0.67$ kbar by Gelles [5]. Our experiments show the pressure required at $22^{\circ} \mathrm{C}$ for initiation of freezing to be $25 \mathrm{kbar}$ for pentane and $29 \mathrm{kbar}$ for 2-methylbutane with equilibrium freezing pressures of $18.2 \pm 0.5 \mathrm{kbar}$ and $22.5 \pm 0.5 \mathrm{kbar}$ respectively.

The equilibrium freezing pressures were determined by over-pressurizing the fluid sufficiently to initiate freezing, then reducing the pressure to partially melt the solid, and then increasing the pressure to partially refreeze the liquid in contact with the solid. The average of the melting pressure and this refreezing pressure is taken as equilibrium freezing pressure. Attempts to determine freezing pressures of various mixtures of the pentanes were unsuccessful. One

\footnotetext{
${ }^{1}$ Figures in brackets indicate the literature references at the end of this paper
}

21 kilobar $=10^{8} \mathrm{~N} / \mathrm{m}^{2}$ mixture of 90 percent pentane-10 percent 2-methylbutane appeared to freeze at 27 kbar but five other attempts to freeze similar mixtures were unsuccessful at pressures of 30 to $39 \mathrm{kbar}$. One mixture of 75 percent pentane-25 percent 2-methylbutane appeared to freeze at $33 \mathrm{kbar}$ but a second mixture failed to freeze at $39 \mathrm{kbar}$. Other mixtures showed no freezing at 39 to 44 kbar. While no satisfactory freezing determinations were made for the mixtures the properties determined for the mixtures as well as the pure substances to $24 \mathrm{kbar}$ are presented. The pure pentanes are in the supercooled (superpressurized) state above their equilibrium freezing pressures.

\section{Low-Pressure Measurements (Atmospheric Pressure)}

The densities of the mixtures were determined by weighing known volumes of the fluids. The same 10 $\mathrm{MHz}$ transducer and electronic equipment which are used for the high pressure ultrasonic measurements, described in reference [3], were arranged with a separate vessel to measure the velocity of sound of the mixtures at atmospheric pressure. The adiabatic bulk modulus, $B_{s}$, is calculated from $B_{s}=\rho c^{2}$ where $\rho$ is the density and $c$ is the velocity of sound. The low pressure dilatomer [1] was used to measure the isothermal bulk modulus of the mixtures. Smoothed values of these results as well as the ratio of the adiabatic to isothermal bulk moduli are given in table 1 for a temperature $22^{\circ} \mathrm{C}$. 
TABle 1. Density, Velocity of Sound, Isothermal and Adiabatic Bulk Moduli, and the Ratio of the Bulk Moduli at Atmospheric Pressure of Mixtures of Pentane and 2-Methylbutane.

\begin{tabular}{c|c|c|c|c|c}
\hline \hline $\begin{array}{c}\text { Ratio of pentane } \\
\text { to 2-methylbutane }\end{array}$ & $\begin{array}{c}\rho \\
\mathrm{kg} / \mathrm{m}^{3}\end{array}$ & $\begin{array}{c}c \\
\mathrm{~m} / \mathrm{s}\end{array}$ & $\begin{array}{c}B_{T}^{*} \\
\mathrm{kbar}\end{array}$ & $\begin{array}{c}B_{s} \\
\mathrm{kbar}\end{array}$ & $B_{s} / B_{T}^{*}$ \\
\hline $0-100$ & 618. & 980 & 4.5 & 5.93 & 1.32 \\
$10-90$ & 618. & 983 & 4.5 & 5.97 & 1.33 \\
$25-75$ & 619. & 990 & 4.6 & 6.07 & 1.32 \\
$50-50$ & 621. & 1000 & 4.9 & 6.21 & 1.27 \\
$75-25$ & 622. & 1012 & 5.1 & 6.37 & 1.25 \\
$90-10$ & 624. & 1016 & 5.1 & 6.44 & 1.26 \\
$100-0$ & 624. & 1020 & 5.1 & 6.49 & 1.27 \\
\hline
\end{tabular}

The density measurements for pentane $\left(624 \mathrm{~kg} / \mathrm{m}^{3}\right)$ and for 2-methylbutane $\left(618 \mathrm{~kg} / \mathrm{m}^{3}\right)$ agree with the values 624 and 620 respectively taken from Bridgman [6] and the values 624 and 618 respectively taken from Timmerman [7].

The velocity of sound measurement for pentane $(1020 \mathrm{~m} / \mathrm{s})$ is in fair agreement with the values, corrected by means of reported temperature dependence to $22{ }^{\circ} \mathrm{C}$, of $999 \mathrm{~m} / \mathrm{s}$ taken from Schaaffs [8], $1015 \mathrm{~m} / \mathrm{s}$ taken from Swanson [9], and $1035 \mathrm{~m} / \mathrm{s}$ taken from Schaaffs [10].

The velocity of sound in 2-methylbutane $(980 \mathrm{~m} / \mathrm{s})$ differs from the value $1007 \mathrm{~m} / \mathrm{s}$ taken from Schaaffs [10] by approximately the amount of the spread of the values for pentane.

The values of isothermal bulk modulus $\left(B_{T}^{*}=\right.$ $-V d p / d V)$ for pentane $(5.1 \mathrm{kbar})$ and 2-methylbutane (4.5 kbar) are greater than the values of $3.0 \mathrm{kbar}$ and 3.1 kbar respectively which were extrapolated from values calculated from Bridgman [6]. The isothermal bulk modulus for 2-methylbutane calculated from data in the International Critical Tables (I.C.T.) [11] is 4.3 kbar.

The ratio of adiabatic to isothermal bulk modulus of 1.27 for pentane agrees with 1.20 taken from Bergman [12] and the ratio of 1.32 for 2-methylbutane agrees with 1.32 taken from I.C.T. [11].

\section{High-Pressure Measurements}

A piston and supported cylinder device which uses a polyethylene (PETH) sleeve to contain the fluid is described in [1] and [3]. The position of the piston is followed by dial gages and appropriate corrections are applied for friction, piston compression, cylinder expansion, and the compression of the polyethylene sleeve. The length of the sample volume and the relative volume of the fluid to the volume at atmospheric pressure is determined. A quartz transducer is bonded to the closure plate in order that an ultrasonic pulse can be sent through the plate. The time difference between the arrival of a partial reflection of the pulse at the first passage from the closure plate to the sample and the arrival after passage through the sample and back is determined by an oscilloscope with a calibrated delay. This time of flight and the length of the sample permit the determination of the velocity of sound in the fluid at pressure. Such measurements were made to maximum pressures of 26 to $44 \mathrm{kbar}$ with various mixtures of the pentanes to measure relative volumes and velocities of sound. These parameters, combined with the low-pressure determinations, were used to determine the bulk moduli and the ratios of the bulk moduli. The values from atmospheric pressure determinations are used for the 0 kbar points in all the tables and figures.

\section{Results}

Figure 1 shows the relative volume, the ratio of the volume at pressure to the volume at atmospheric pressure $\left(V / V_{0}\right)$, of individual samples of pentane and of 2-methylbutane. The volume change at 25 and 29 kbar respectively show the freezing at overpressurization. Figure 2 shows the relative volumes at

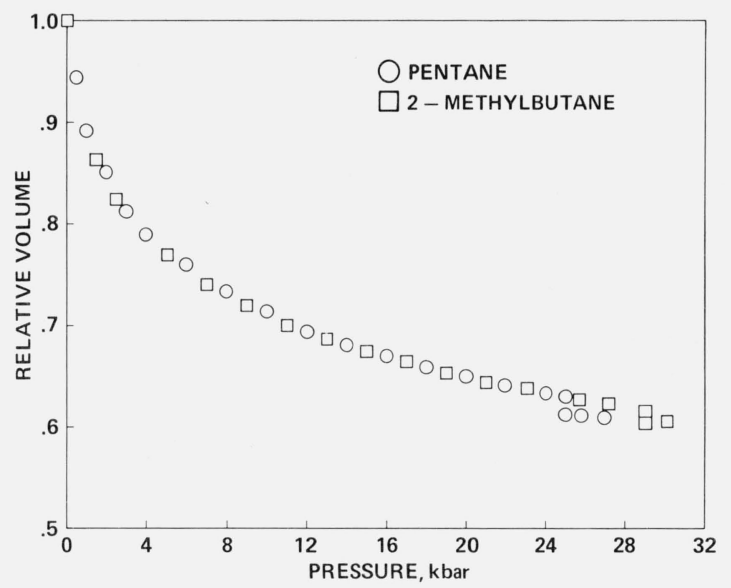

FIGURE 1. Relative volumes of pentane and 2-methylbutane showing freezing.

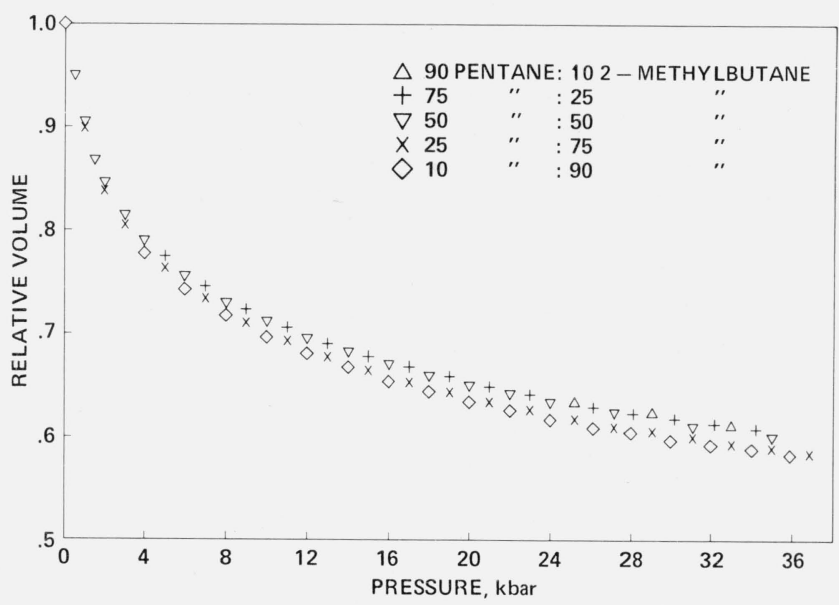

FIGURE 2. Relative volumes of mixtures of pentane and 2-methylbutane to 24 kbar. 
TABLE 2. Ratio of $\mathrm{V} / \mathrm{V}_{0}$

\begin{tabular}{c|r|r|r|r|r|r|r}
\hline \hline \multirow{2}{*}{$\begin{array}{c}\text { Pressure } \\
\text { in } \\
\text { kilobars }\end{array}$} & \multicolumn{7}{|c}{ Ratio of pentane to 2-methylbutane } \\
\cline { 2 - 8 } & $100-0$ & $90-10$ & $75-25$ & $50-50$ & $25-75$ & $10-90$ & $0-100$ \\
\hline 0 & 1.000 & 1.000 & 1.000 & 1.000 & 1.000 & 1.000 & 1.000 \\
2 & .848 & .847 & .847 & .846 & .838 & .838 & .841 \\
4 & .794 & .790 & .790 & .790 & .780 & .779 & .787 \\
6 & .761 & .756 & .756 & .756 & .747 & .746 & .754 \\
8 & .738 & .731 & .731 & .732 & .722 & .721 & .730 \\
10 & .719 & .712 & .711 & .713 & .702 & .701 & .711 \\
12 & .702 & .695 & .696 & .697 & .686 & .685 & .696 \\
14 & .689 & .682 & .681 & .683 & .672 & .672 & .683 \\
16 & .678 & .669 & .670 & .672 & .660 & .660 & .671 \\
18 & .667 & .659 & .659 & .661 & .649 & .649 & .661 \\
20 & .658 & .649 & .649 & .651 & .640 & .640 & .652 \\
22 & .650 & .641 & .639 & .643 & .631 & .631 & .643 \\
24 & .643 & .633 & .633 & .635 & .623 & .624 & .636 \\
\hline
\end{tabular}

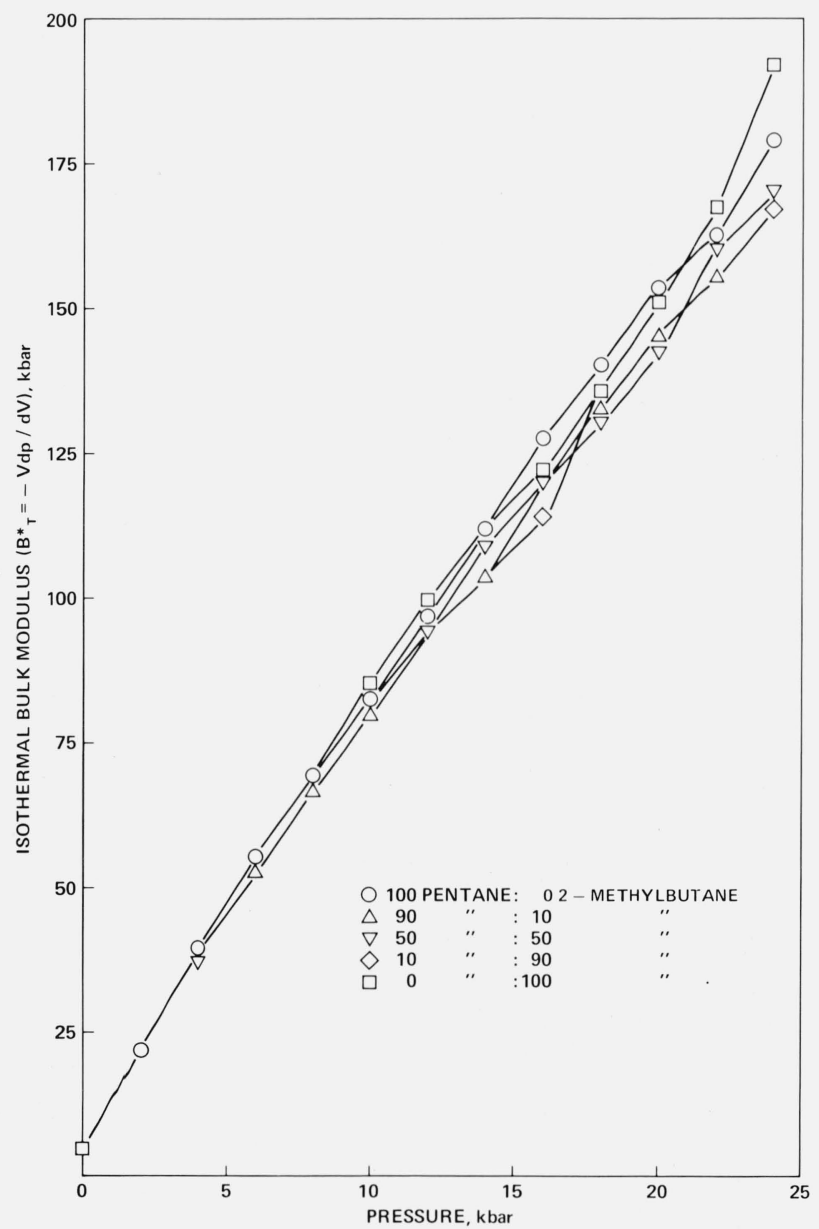

FiguRE 3. Isothermal bulk modulus $\left(\mathrm{B}_{\mathrm{T}}^{*}=-\mathrm{V} \mathrm{dp} / \mathrm{dV}\right)$ of mixtures of pentane and 2-methylbutane to $24 \mathrm{kbar}$.

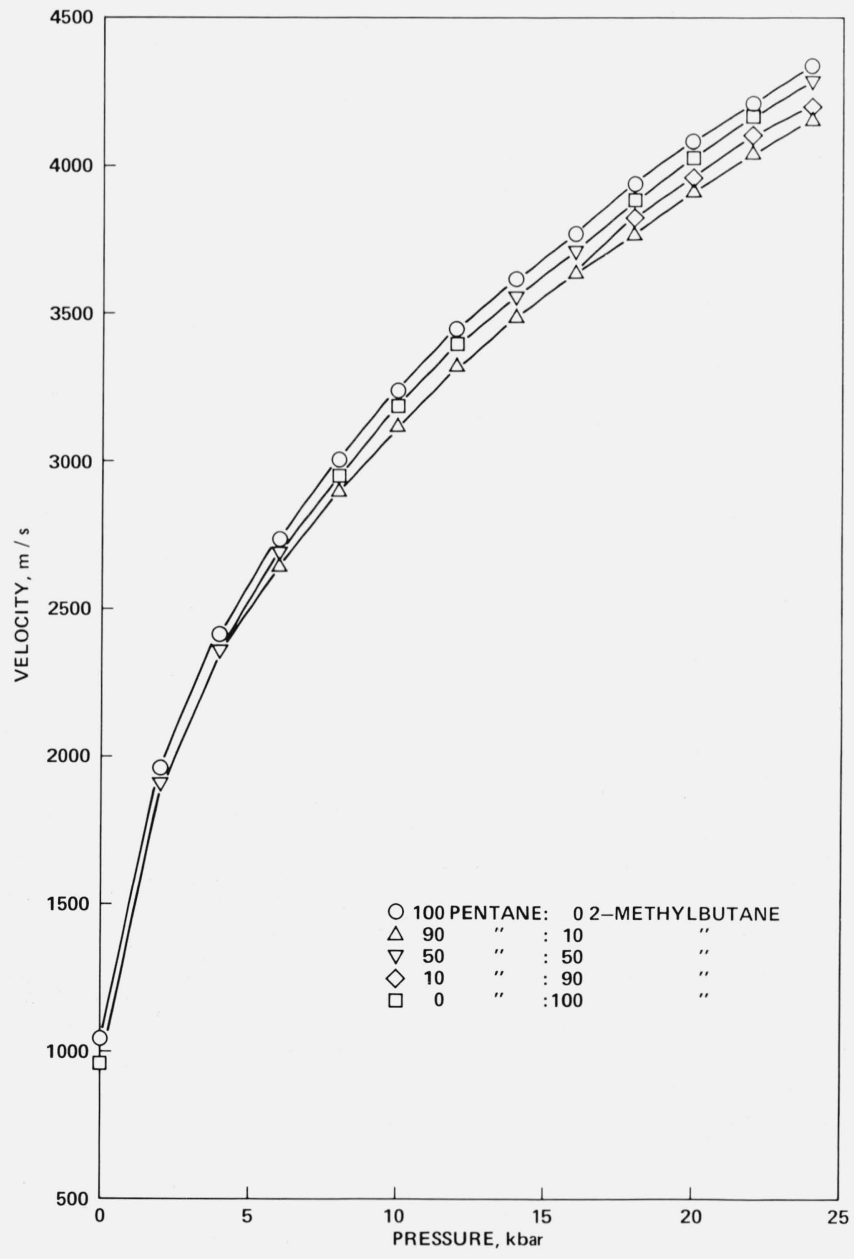

FIGURE 4. Velocity of sound of mixtures of pentane and 2-methylbutane to 24 kbar. 
pressure of individual runs on mixtures of pentane and 2-methylbutane. Table 2 shows the relative volumes at selected pressures of pentane and 2-methylbutane and their mixtures. Tables 2 through 6 and figures 3 through 6 contain results averaged from five

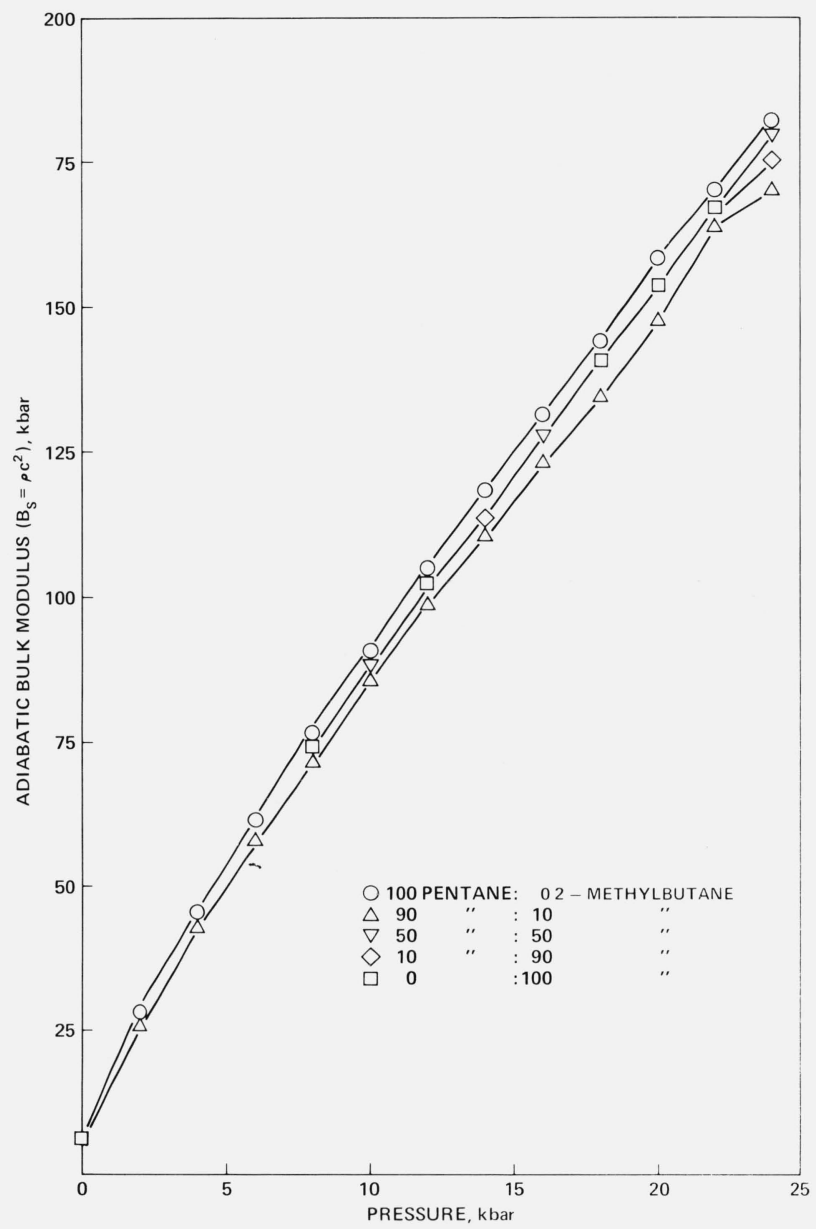

FigURE 5. Adiabatic bulk modulus $\left(\mathrm{B}_{\mathrm{s}}=\rho \mathrm{c}^{2}\right)$ of mixtures of pentane and 2-methylbutane to 24 kbar.

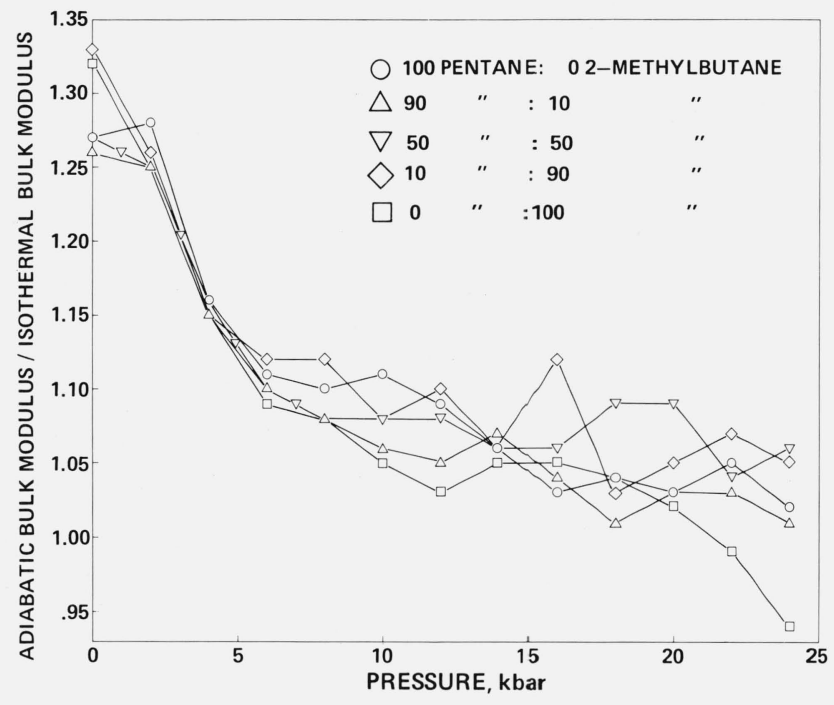

FIGURE 6. Ratio of adiabatic to isothermal bulk moduli $\left(\mathrm{B}_{\mathrm{s}} / \mathrm{B}_{\mathrm{T}}^{*}=\right.$ $\mathrm{c}_{\mathrm{p}} / \mathrm{c}_{\mathrm{v}}=1+\mathrm{T} \alpha^{2} \mathrm{c}^{2} / \mathrm{c}_{\mathrm{p}}$ ) of mixtures of pentane and 2-methylbutane to 24 kbar.

runs each for pentane, 2-methylbutane, and the 90 pentane to 102 -methylbutane mixture; the results given for other mixtures are from single experiments. Table 3 and figure 3 show the isothermal bulk modulus $\left(B_{T}^{*}=-V d p / d V\right)$. Table 4 and figure 4 show the velocity of sound in meters per second. Table 5 and figure 5 show the adiabatic bulk modulus $\left(B_{s}=\rho c^{2}\right)$. Table 6 and figure 6 show the ratio of the adiabatic bulk modulus to the isothermal bulk modulus,

$$
B_{s} / B_{T}^{*}=c_{p} / c_{v}=1+T \alpha^{2} c^{2} / c_{p},
$$

where $\alpha$ is the thermal expansivity, $c_{p}$ the specific heat at constant pressure, and $c_{v}$ the specific heat at constant volume. The total spread at $24 \mathrm{kbar}$ for the five pentane runs is 2.4 percent in relative volume, 5.5 percent in velocity, 11 percent in isothermal bulk modulus, and 10.5 percent in adiabatic bulk modulus; for the five 2-methylbutane runs it is $1.1,2,9$ and 5

TABLE 3. Isothermal Bulk Modulus (-Vdp/dV) in Kilobars

\begin{tabular}{c|r|r|r|r|r|r|r}
\hline \hline \multirow{2}{*}{$\begin{array}{c}\text { Pressure } \\
\text { in } \\
\text { kilobars }\end{array}$} & \multicolumn{7}{|c}{ Ratio of pentane to 2-methylbutane } \\
\cline { 2 - 8 } & $100-0$ & $90-10$ & $75-25$ & $50-50$ & $25-75$ & $10-90$ & $0-100$ \\
\hline 0 & 5.1 & 5.1 & 5.1 & 4.7 & 4.6 & 4.5 & 4.5 \\
2 & 22.3 & 21.3 & 21.5 & 21.3 & 21.1 & 20.4 & 21.9 \\
4 & 39.6 & 37.5 & 37.4 & 37.7 & 36.9 & 37.0 & 38.8 \\
6 & 55.6 & 52.8 & 52.9 & 54.1 & 51.8 & 52.2 & 55.0 \\
8 & 69.4 & 66.8 & 66.6 & 68.6 & 64.6 & 65.2 & 68.8 \\
10 & 82.4 & 80.4 & 81.8 & 81.9 & 79.4 & 81.8 & 85.0 \\
12 & 97.1 & 93.7 & 92.5 & 94.9 & 91.9 & 91.8 & 99.5 \\
14 & 112.0 & 103.8 & 106.6 & 109.0 & 104.6 & 107.8 & 111.6 \\
16 & 127.7 & 118.6 & 119.4 & 120.5 & 114.6 & 114.8 & 122.1 \\
18 & 140.3 & 133.1 & 130.5 & 130.3 & 131.8 & 135.3 & 136.2 \\
20 & 153.6 & 144.1 & 139.0 & 142.5 & 142.1 & 144.6 & 151.6 \\
22 & 162.7 & 155.5 & 153.7 & 160.5 & 149.7 & 155.4 & 168.9 \\
24 & 179.4 & 168.7 & 169.7 & 170.7 & 162.5 & 167.3 & 192.3 \\
\hline
\end{tabular}


TABLE 4. Velocity of Sound in Meters per Second

\begin{tabular}{c|c|c|c|c|c|c|c}
\hline \hline \multirow{2}{*}{$\begin{array}{c}\text { Pressure } \\
\text { in } \\
\text { kilobars }\end{array}$} & \multicolumn{7}{|c}{ Ratio of pentane to 2-methylbutane } \\
\cline { 2 - 7 } & $100-0$ & $90-10$ & $75-25$ & $50-50$ & $25-75$ & $10-90$ & $0-100$ \\
\hline 0 & 1020 & 1016 & 1012 & 1000 & 990 & 983 & 980 \\
2 & 1963 & 1900 & 1909 & 1903 & 1884 & 1860 & 1929 \\
4 & 2416 & 2336 & 2343 & 2355 & 2323 & 2315 & 2383 \\
6 & 2741 & 2650 & 2670 & 2698 & 2644 & 2650 & 2710 \\
8 & 3004 & 2902 & 2918 & 2955 & 2901 & 2915 & 2971 \\
10 & 3238 & 3123 & 3148 & 3181 & 3138 & 3147 & 3209 \\
12 & 3444 & 3319 & 3336 & 3391 & 3333 & 3343 & 3401 \\
14 & 3623 & 3488 & 3515 & 3560 & 3521 & 3525 & 3602 \\
16 & 3782 & 3633 & 3659 & 3713 & 3704 & 3705 & 3742 \\
18 & 3935 & 3773 & 3800 & 3891 & 3829 & 3834 & 3890 \\
20 & 4091 & 3921 & 3954 & 4033 & 3939 & 3971 & 4033 \\
22 & 4215 & 4048 & 4089 & 4161 & 4072 & 4113 & 4177 \\
24 & 4336 & 4161 & 4226 & 4297 & 4226 & 4214 & 4316 \\
\hline
\end{tabular}

TABle 5. Adiabatic Bulk Modulus in Kilobars

\begin{tabular}{c|r|r|r|r|r|r|r}
\hline \hline \multirow{2}{*}{$\begin{array}{c}\text { Pressure in } \\
\text { kilobars }\end{array}$} & \multicolumn{7}{|c}{ Ratio of pentane to 2-methylbutane } \\
\cline { 2 - 7 } & $100-0$ & $90-10$ & $75-25$ & $50-50$ & $25-75$ & $10-90$ & $0-100$ \\
\hline 0 & 6.5 & 6.4 & 6.4 & 6.2 & 6.1 & 6.0 & 5.9 \\
2 & 28.4 & 26.6 & 26.8 & 26.6 & 26.3 & 25.6 & 27.4 \\
4 & 45.9 & 43.1 & 43.3 & 43.7 & 42.9 & 42.6 & 44.6 \\
6 & 61.6 & 58.0 & 58.8 & 59.8 & 58.0 & 58.3 & 60.1 \\
8 & 76.3 & 71.8 & 72.6 & 74.0 & 72.3 & 73.0 & 74.5 \\
10 & 91.1 & 85.5 & 86.6 & 88.1 & 86.9 & 87.4 & 89.3 \\
12 & 105.3 & 98.8 & 99.6 & 102.4 & 100.4 & 100.9 & 102.4 \\
14 & 118.8 & 111.3 & 112.8 & 117.9 & 114.3 & 114.5 & 117.1 \\
16 & 131.6 & 122.9 & 124.4 & 127.4 & 128.8 & 128.6 & 128.5 \\
18 & 144.6 & 134.7 & 136.4 & 142.1 & 139.9 & 140.0 & 141.1 \\
20 & 158.4 & 147.6 & 149.8 & 154.9 & 150.2 & 152.4 & 153.8 \\
22 & 170.4 & 159.4 & 162.4 & 167.1 & 162.8 & 165.6 & 167.0 \\
24 & 182.3 & 170.5 & 175.6 & 180.3 & 177.6 & 176.0 & 180.3 \\
\hline
\end{tabular}

TABLE 6. Ratio of Adiabatic Bulk Modulus to Isothermal Bulk Modulus

\begin{tabular}{c|c|c|c|c|c|c|c}
\hline \hline \multirow{2}{*}{$\begin{array}{c}\text { Pressure in } \\
\text { kilobars }\end{array}$} & \multicolumn{7}{|c}{ Ratio of pentane to 2-methylbutane } \\
\cline { 2 - 7 } & $100-0$ & $90-10$ & $75-25$ & $50-50$ & $25-75$ & $10-90$ & $0-100$ \\
\hline 0 & 1.27 & 1.26 & 1.25 & 1.27 & 1.32 & 1.33 & 1.32 \\
2 & 1.28 & 1.25 & 1.24 & 1.25 & 1.25 & 1.26 & 1.25 \\
4 & 1.16 & 1.15 & 1.16 & 1.16 & 1.16 & 1.15 & 1.15 \\
6 & 1.11 & 1.10 & 1.10 & 1.10 & 1.12 & 1.12 & 1.09 \\
8 & 1.10 & 1.08 & 1.09 & 1.08 & 1.12 & 1.12 & 1.08 \\
10 & 1.11 & 1.06 & 1.06 & 1.08 & 1.10 & 1.07 & 1.05 \\
12 & 1.09 & 1.05 & 1.07 & 1.08 & 1.09 & 1.10 & 1.03 \\
14 & 1.06 & 1.07 & 1.06 & 1.06 & 1.09 & 1.06 & 1.05 \\
16 & 1.03 & 1.04 & 1.04 & 1.06 & 1.12 & 1.12 & 1.05 \\
18 & 1.04 & 1.01 & 1.05 & 1.09 & 1.04 & 1.03 & 1.04 \\
20 & 1.03 & 1.03 & 1.08 & 1.09 & 1.06 & 1.05 & 1.02 \\
22 & 1.05 & 1.03 & 1.06 & 1.04 & 1.09 & 1.07 & .99 \\
24 & 1.02 & 1.01 & 1.04 & 1.06 & 1.09 & 1.05 & .94 \\
\hline
\end{tabular}


percent respectively; and for the five 90 pentane to 10 2-methylbutane mixture it is $2,2,16$ and 3 percent respectively. Tables 2 through 6 and figures 3 through 6 are terminated at 24 kbar because at higher pressures the scatter of the data increases greatly. The increasing stiffness and decreasing volume of the sample with pressure cause the corrections and uncertainties due to piston-stack compression, cylinder expansion, and PETH compression to increase their effect on the measurements.

The effect of estimated uncertainty of input data on the relative uncertainty of the measured values of relative volume, velocity, adiabatic modulus, and isothermal modulus at $24 \mathrm{kbar}$ is shown in table 7 . or 2-methylbutane froze. Also no satisfactory signal was present above $27 \mathrm{kbar}$ in the mixtures. While these mixtures were not frozen and Piermarini et al. [14] show the glass transition to be 70 kbar for a 50 pentane 50 2-methylbutane mixture, the viscosity increase so attenuates the signal that although the impedance match is improving, the signal decreases to a less than usable magnitude.

The mixtures serve as useful high pressure fluids. Since there appears to be no reason to choose any one ratio above another in terms of compressibility or viscosity, the 50-50 mixture would appear a reasonable choice for maximum pressure use based on its high glass transition pressure.

TABle 7. Estimated Relative Systematic Uncertainties at 24 Kilobars Due to Uncertainties in Input Data

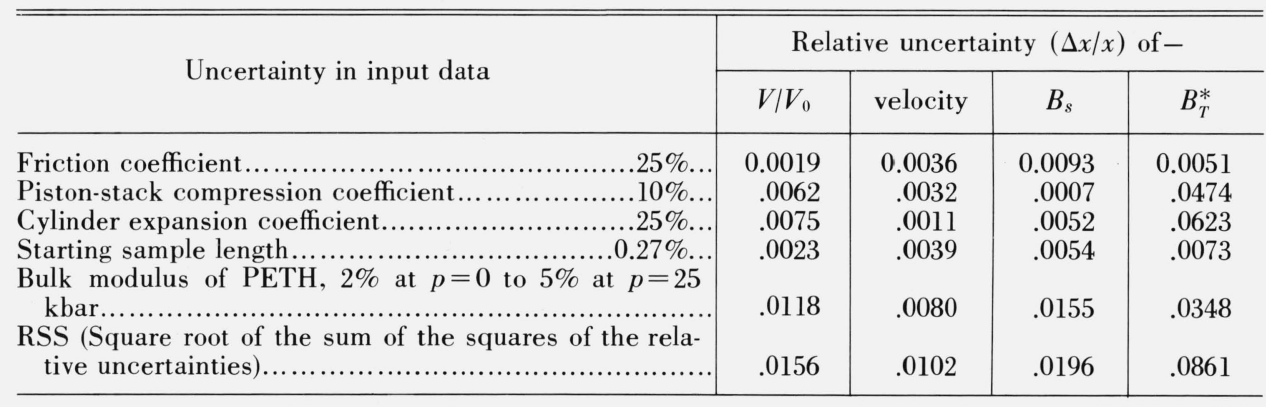

The uncertainty attributed to a change of 2 percent at $p=0$ and 5 percent at $p=25$ kbar in the PETH bulk modulus also includes a small uncertainty due to using a simplified form of $B_{T}$ (PETH) $=B_{0}+B_{1} P$ rather than a better representation of $B_{T}(\mathrm{PETH})=$ $B_{0}+B_{1} P+C e^{-0.28 p}$ given in reference [13]. A source of some of the scatter between the runs shown above, and not fully taken into account in the uncertainty table, is the amount of liquid in the system when the PETH sleeve seals between the piston and the closure plate. Variation in the initial sealing results in an improper value for sample length and an improper value for the zero friction coefficient. Runs which seal very poorly are spotted and discarded; however, smaller variations contribute to scatter and to the difficulty of extrapolating to zero pressure and are partially responsible for the necessity of separate determination of the zero pressure values.

The measurement of the velocity of sound was limited by the quality of the signal. The poor impedance match between the tungsten carbide closure plate and the fluids which gives a combined coefficient for transmission, reflection, and transmission of $5.6 \times 10^{-4}$ at $p=0$ improves to $2.03 \times 10^{-2}$ at $p=24$ kbar. No signal could be detected after the pentane

\section{References}

[1] Houck, J. C., and Heydemann, P., J. Res. Nat. Bur. Stand. (U.S.), 75A (Phys. and Chem.), No. 2, 121-127 (Mar.-Apr. 1971).

[2] Zeto, R. J., and Vanfleet, H. B., J. Appl. Phys. 40, 2227 (1969).

[3] Heydemann, P., and Houck, J. C., Nat. Bur. Stand. (U.S.), Spec. Publ. 326, 343 pages, (Mar. 1971). Proc. Symp. Accurate characterization of the high-pressure environment, Gaithersburg, Md., 1968.

[4] Reeves, L. E., Scott, G. J., and Babb, S. E. Jr., J. Chem. Phys. 40, No. 12, 3662 (1964).

[5] Gelles, S. H., J. Chem. Phys. 48, 526 (1968).

[6] Bridgman, P. W., Proc. Am. Acad. Arts Sci. 66, 198-200 (1931).

[7] Physio-Chemical-Constants of Pure Organic Compounds, Timmermans, J., (Elsevier Publishing Co., Inc., New York, 1950), pages 30-40.

[8] Schaaffs, W., Z. Physik, Chem. 194, 31 (1944).

[9] Swanson, J. C., J. Chem. Phys. 2, 689 (1934).

[10] Schaaffs, W., Z. Physik, Chem. 196, 413 (1951).

[11] International Critical Tables, E. W. Washburn (McGraw-Hill Book Co., N.Y., Vol. III, 1928), pages 38-39.

[12] Ultrasonics, L. Bergman (G. Bell and Sons Ltd., London, 1938), page 124 .

[13] Heydemann, P. L. M., and Houck, J. C., J. Polymer Science, Part A-2, 10, 1631-1637 (1972).

[14] Piermarini, G. J., Block, S., and Barnett, J. D., JAP 445377 (1973).

(Paper 78A5-836) 